\title{
Pyrrolidine Dithiocarbamate (PDTC) Attenuates Luteolin-Induced Apoptosis in Human Leukemia HL-60 Cells*
}

\author{
Ming-Fen Lee ${ }^{1}$, Cheng-Ta Li ${ }^{2}$, Ming-Dian Chen ${ }^{1}$, An-Chin Cheng ${ }^{1 \#}$ \\ ${ }^{1}$ Department of Nutrition and Health Sciences, Chang Jung Christian University, Tainan, Chinese Taipei; ${ }^{2}$ Department of Nutrition \\ and Health Science, Fooyin University, Kaohsiung, Chinese Taipei. \\ Email: \#anniecheng@mail.cjcu.edu.tw
}

Received September $14^{\text {th }}, 2012$; revised October $16^{\text {th }}, 2012$; accepted October $27^{\text {th }}, 2012$

\begin{abstract}
Studies have indicated that flavonoid luteolin is a potential inhibitor of tumor cell proliferation and may function as an anticarcinogenic agent. Pyrrolidine dithiocarbamate (PDTC), a synthetic compound, may exhibit biphasic effects on apoptosis depending on the experimental context. Previously, we found that luteolin induced the activation of the proapoptotic proteins, such as Bad, Bid, and Bax, in HL-60 human leukemia cells. We also explored the modulatory effects and molecular mechanisms of PDTC on the cytotoxicity of luteolin in HL-60 cells; PDTC could interfere with luteolin's ability to cleave poly(ADP-ribose)-polymerase (PARP) and DNA fragmentation of factor-45 (DFF-45). In the current study, we further investigated the effect of PDTC on the luteolin-induced death-receptor pathway and the cleavage of the Bcl-2 family members. We found that the combination of luteolin and PDTC increased the survival of the HL-60 cells such that PDTC inhibited both extrinsic and intrinsic pathways in luteolin-induced apoptosis.
\end{abstract}

Keywords: Apoptosis; Pyrrolidine Dithiocarbamate; HL-60 Cells; Luteolin; Death-Receptor Pathway; Bcl-2 Family

\section{Introduction}

Flavonoids are biologically active polyphenolic compounds, which are widely distributed in plants [1]. Cell culture experiments, animal models, and human studies have shown that flavonoids may prevent cancer progresssion by inhibiting cell proliferation and inducing apoptosis [2-4]. Luteolin (shown in Figure 1), a subtype of flavonoids, can be found in large amounts in herbs and is also present in many types of fruits and vegetables [5]. Many studies have indicated that luteolin is a potential inhibitor of tumor cell proliferation and may function as an anticarcinogenic agent [6-10]. In our previous study, luteolin was able to decrease the mitochondrial membrane potential, trigger the release of cytochrome $c$ to cytosol, and subsequently induce the processing of procaspase- 9 and procaspase- 3 , which led to the cleavage of poly(ADP-ribose)polymerase (PARP) and DNA fragmentation of factor-45 (DFF-45) [11]. In addition, luteolin induced the cleavage of the pro-apoptotic Bcl-2 family members and the cleavage of the anti-apoptotic Bcl-2 family proteins into their pro-apoptotic fragments [11].

Pyrrolidine dithiocarbamate (PDTC) (shown in Figure

\footnotetext{
*The authors declare no conflict of interest for this manuscript.
}

"Corresponding author.
1) is a synthetic compound, which is largely used in the studies of cell biology and molecular biology. PDTC belongs to a group of dithiocarbamates, which is known to exert antioxidant and radical scavenger functions [12-15] as well as pro-oxidant properties [16-18]. PDTC may inhibit or induce apoptosis; its effect on apoptosis depends on the experimental context, including cell types, density, and the presence of $\mathrm{Cu}$ and $\mathrm{Zn}$ [19]. PDTC has been shown to be an inhibitor of agonist-induced apoptosis in human leukemia HL-60 cells and thymocytes [20]. PDTC may inhibit the activation of nuclear factor kappa B (NF- $k$ B) $[20,21]$, block actinomycin-D induced apoptosis [22], and suppress flavone-induced cytotoxic effect [23]. Another study indicated that PDTC could inhibit cytochrome $c$ release, caspase-3 activity, and PARP cleavage [24]. In contrast, previous studies have also shown that PDTC induced cytochrome $c$ release from mitochondria [25] and PDTC potentiated TNFalpha-stimulated apoptosis signaling through a Bcl-2regulated mechanism [26]. PDTC may also block ionizing radiation-induced apoptosis in freshly-isolated normal mouse spleen cells [27]. Because of its apoptosisinducing capability, PDTC has been proposed as an anticancer agent [25].

Previously we found that PDTC inhibited the luteolin- 


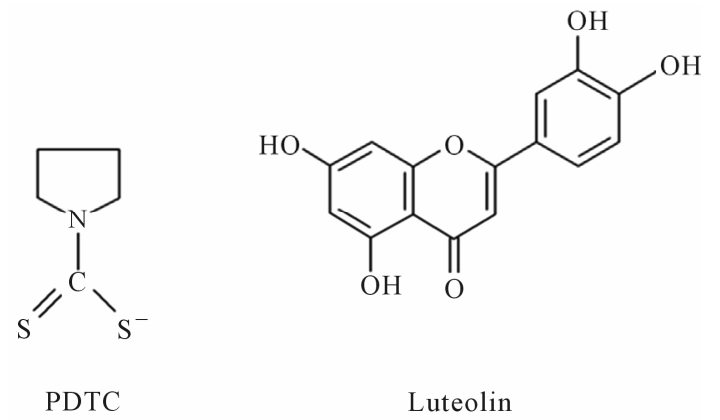

Figure 1. Structures of PDTC and luteolin.

induced apoptosis by modulating Akt, which phosphorylated and reduced the activity of caspase- 9 and had not completely interfered with luteolin's ability to change the mitochondrial membrane potential or its ability to trigger the release of cytochrome $c$ to cytosol, suggesting that PDTC might not inhibit luteolin-induced apoptosis through blocking the mitochondrial apoptotic pathway [28]. In the current study, we further investigate the effect of PDTC on the luteolin-induced death-receptor pathway and on the cleavage of the Bcl-2 family members. We found that PDTC not only inhibited the cleavage of the pro-apoptotic Bcl-2 family members and the cleavage of the anti-apoptotic Bcl-2 family proteins into their pro-apoptotic fragments but also blocked the extrinsic pathway in luteolin-induced apoptosis in HL-60 cells. These findings provide insights when designing and employing therapeutic strategy using the combination of flavonoids and antioxidants such as PDTC in human cancers.

\section{Materials and Methods}

\subsection{Study Design}

In this study, we investigated the effect of PDTC on the luteolin-induced death-receptor pathway and on the cleavage of the Bcl-2 family members. Human leukemia HL-60 cells were treated with various doses $(0-100 \mu \mathrm{M})$ of luteolin for $12 \mathrm{~h}$ and a fixed dose $(60 \mu \mathrm{M})$ at different time points $(0-12 \mathrm{~h})$ to follow the effect of lutolin on dose-responsive and time-course patterns of apoptosis as examined by the expression of the proapoptotic proteins, respectively. The optimal condition of luteolin treatment to exhibit apoptosis was then determined at $60 \mu \mathrm{M}$ for 12 $\mathrm{h}$, which was used to determine the dose of PDTC for the subsequent experiments to study the combined effect of luteolin and PDTC. The effect on apoptosis of PDTC pretreatment followed by luteolin was compared with that of luteolin treatment alone by measuring DNA fragmentation, apoptotic bodies, and proapoptotic proteins. A potential model for the findings was proposed accordingly.

\subsection{Chemicals and Antibodies}

Luteolin was obtained from Versuchsstation Schweizerischer Brauereien (Zürich, Switzerland) and dissolved in dimethyl sulfoxide (DMSO) prior to use. PDTC was obtained from Sigma Chemical Co. (St. Louis, MO). The antibodies to Bax were obtained from Santa Cruz Biotechnology (Santa Cruz, CA); anti-Fas, anti-caspase-8, anti-Bad, and anti-Bid antibodies were from Pharmingen (San Diego, CA); anti-Bcl- $\mathrm{X}_{\mathrm{L}}$ antibodies were purchased from Transduction Laboratory (Lexington, KY). Horseradish peroxidase-conjugated anti-mouse and rabbit IgG secondary antibodies were obtained from Sigma.

\subsection{Cell Culture}

Human leukemia HL-60 cell lines were obtained from American Type Culture Collection (Rockville, MD) and maintained in RPMI-1640, supplemented with 15\% fetal calf serum (Gibco BRL, Grand Island, NY), 100 units/ $\mathrm{mL}$ of penicillin, $100 \mu \mathrm{g} / \mathrm{mL}$ of streptomycin, and $2 \mathrm{mM}$ L-glutamine (Life Technologies, Inc., Grand Island, NY) and kept at $37^{\circ} \mathrm{C}$ in a humidified atmosphere of $5 \% \mathrm{CO}_{2}$.

\subsection{Acridine Orange Staining Assay}

HL-60 Cells $\left(5 \times 10^{5}\right)$ were seeded into $60-\mathrm{mm}$ cell culture dishes and incubated at $37^{\circ} \mathrm{C}$. The cells were harvested after $24 \mathrm{~h}$ and $5 \mu \mathrm{L}$ of cell suspension was mixed on a slide with an equal volume of acridine orange solution at a concentration of $10 \mu \mathrm{g}$ per milliliter in phosphate-buffered saline (PBS). Green fluorescence was detected between 500 and $525 \mathrm{~nm}$ using an Olympus microscope (Olympus America, Lake Success, NY). Bright-staining condensed chromatin was detective of apoptosis.

\subsection{DNA Extraction and Electrophoresis}

HL-60 cells $\left(2 \times 10^{5}\right.$ cells $\left./ \mathrm{mL}\right)$ were harvested, washed with PBS, and then lysed with digestion buffer containing $0.5 \%$ sarkosyl, $0.5 \mathrm{mg} / \mathrm{mL}$ proteinase $\mathrm{K}, 50 \mathrm{mM}$ Tris (hydroxymethyl) aminomethane ( $\mathrm{pH} 8.0)$, and $10 \mathrm{mM}$ EDTA at $56^{\circ} \mathrm{C}$ for $3 \mathrm{~h}$. They were treated with RNase A $(0.5 \mu \mathrm{g} / \mathrm{mL})$ for another $2 \mathrm{~h}$ at $56^{\circ} \mathrm{C}$. The DNA was extracted by phenol/chloroform/isoamyl alcohol (25/24/1) before loading and analyzed by $2 \%$ agarose gel electrophoresis. The agarose gels were run at $50 \mathrm{~V}$ for $120 \mathrm{~min}$ in Tris-borate/EDTA buffer. About $20 \mu \mathrm{g}$ of DNA was loaded in each well and observed and photographed under UV light.

\subsection{Western Blotting}

HL-60 cells were first treated with $60 \mu \mathrm{M}$ luteolin or 
pretreated with $50 \mu \mathrm{M}$ PDTC for $0.5 \mathrm{~h}$ followed by 60 $\mu \mathrm{M}$ luteolin treatment for $12 \mathrm{~h}$. They were then harvested and homogenized in a lysis buffer $(50 \mathrm{mM}$ Tris- $\mathrm{HCl}, \mathrm{pH}$ 8.0; 5 mM EDTA; $150 \mathrm{mM} \mathrm{NaCl} ; 0.5 \%$ NP-40; $0.5 \mathrm{mM}$ phenylmethylsulfonyl fluoride; and $0.5 \mathrm{mM}$ dithiothreitol) for $30 \mathrm{~min}$ on ice. The lysed cells were centrifuged at $10,000 \times \mathrm{g}$ at $4^{\circ} \mathrm{C}$ for $30 \mathrm{~min}$. The proteins in the supernatant were measured by bicinchoninic acid assay. Briefly, $50 \mu \mathrm{g}$ of total cellular proteins was resolved by sodium dodecyl sulfate-polyacrylamide gel electrophoresis $(10 \%$ for caspases- 8 and $\alpha$-tubulin; $12.5 \%$ for Fas; $15 \%$ for Bid, Bcl- $\mathrm{X}_{\mathrm{L}}, \mathrm{Bad}$, and Bax), transferred onto polyvinylidene difluoride membranes (Amersham, Arlington, IL), and then probed with respective primary antibodies followed by the addition of horseradish peroxidase-labeled secondary antibodies. The expression of protein was detected by measuring the chemiluminescence of the blotting agent (Amersham, Arlington, IL); the membranes were exposed to Kodak X-Omat films.

\section{Results}

\subsection{Luteolin Induced Caspase-8 Activation and Bid Cleavage in HL-60 Human Leukemia Cells}

In the presence of luteolin, the cleavage of pro-caspase- 8 exhibited both time-course and dose-dependent manners in HL-60 cells (Figure 2). The cleavage of Bid also followed similar trends as in the case of caspase-8 (Figure 2). These observations indicated the activation of the extrinsic pathway by luteolin.

\subsection{PDTC Inhibition of Luteolin-Induced Apoptotic Bodies and DNA Fragmentation}

When treated with $60 \mu \mathrm{M}$ luteolin, HL-60 cells exhibited significant morphological changes and chromosomal condensation; whereas the presence of the apoptotic bodies was significantly abolished by the pretreatment of $50 \mu \mathrm{M}$ PDTC (Figure 3(a)). In addition, PDTC inhibited luteolin-induced DNA fragmentation in a dose-dependent manner (Figure 3(b)).

\subsection{PDTC Reduction of Luteolin-Induced Fas Expression, Caspase-8 Activation, and Bid Cleavage}

We further studied the effect of PDTC on the luteolininduced activation of the extrinsic pathway in HL-60 cells. As indicated in Figure 4, the expression of Fas and the cleavage products of pro-caspase- 8 and Bid decreased when HL-60 cells were treated with both luteolin and PDTC. The results indicated that PDTC inhibited the luteolin-induced extrinsic pathway.

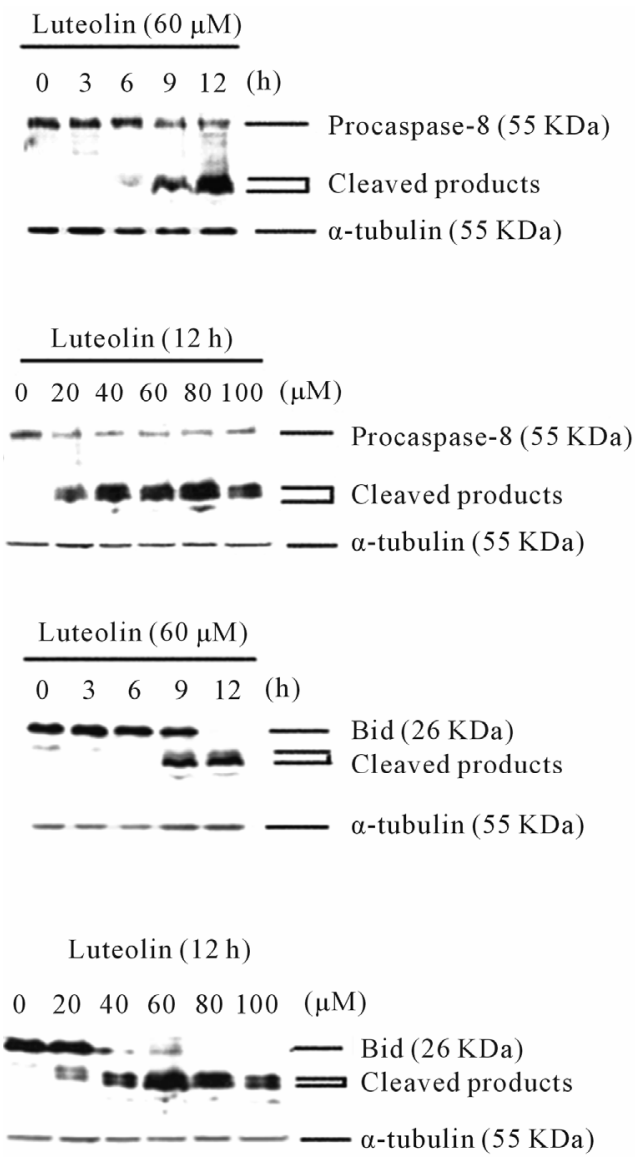

Figure 2. Luteolin induced the cleavage and activation of caspase- 8 and Bid in dose-responsive and time-dependent manners. The processing of procaspase- 8 and the expression of Bid were detected by Western blotting using specific antibodies against caspase-8 and Bid, respectively.

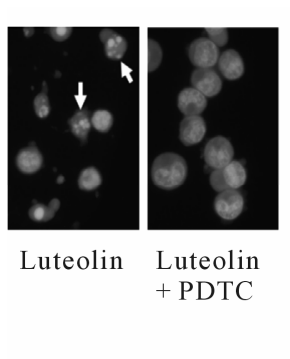

(a)

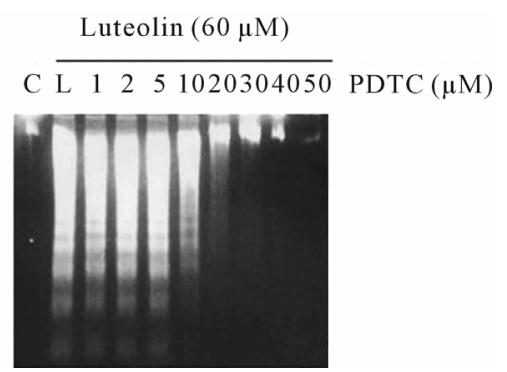

(b)
Figure 3. Effects of PDTC on luteolin-induced morphological changes and DNA fragmentation. (a) HL-60 cell were treated with $60 \mu \mathrm{M}$ luteolin for $12 \mathrm{~h}$ with or without preincubation of $50 \mu \mathrm{M}$ PDTC for $0.5 \mathrm{~h}$. The condensed chromosomes are seen as spots in the nucleus by acridine orange staining; apoptotic cells are shown as white arrowheads; (b) HL-60 cells were pretreated with various concentrations of PDTC as indicated for $0.5 \mathrm{~h}$ before incubating with luteolin for $12 \mathrm{~h}$. Internucleosomal DNA fragmentations were analyzed by agarose electrophoresis. C: control, L: luteolin only. 


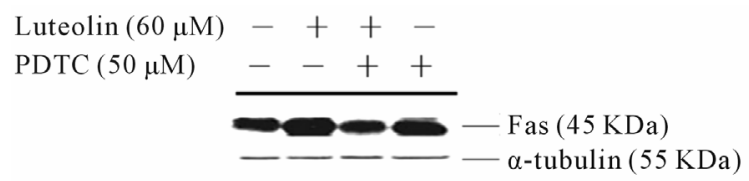

Luteolin $(60 \mu \mathrm{M})-++$

$\operatorname{PDTC}(50 \mu \mathrm{M})--++$

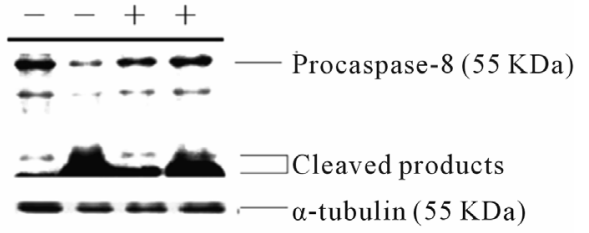

Luteolin $(60 \mu \mathrm{M})-++$

$\operatorname{PDTC}(50 \mu \mathrm{M}) \quad-\quad++$

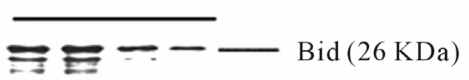

- $\quad$ Cleaved products

$---\alpha$-tubulin (55 KDa)

Figure 4. Luteolin induced the expression of Fas and the cleavage and activation of caspase-8 and Bid, and these induction effects were suppressed by PDTC in HL-60 cells. HL-60 cells were treated with DMSO, $60 \mu \mathrm{M}$ luteolin, 50 $\mu M$ PDTC followed by $60 \mathrm{mM}$ luteolin, or $50 \mu \mathrm{M}$ PDTC. The expression of Fas, caspase-8, and Bid was analyzed by Western blotting as described in the Materials and Methods section.

\subsection{Blocking of Luteolin-Induced Cleavage of Pro-Apoptotic and Anti-Apoptotic Members of the Bcl-2 Family by PDTC}

As shown in Figure 5, in the presence of PDTC, the expression of Bax was blocked and the level of Bad protein was slightly decreased. The cleaved products of Bax, $\mathrm{Bad}$, and $\mathrm{Bcl}-\mathrm{X}_{\mathrm{L}}$ were detected in the luteolin-treated HL-60 cells; however, there were no visible cleaved products of $\mathrm{Bax}, \mathrm{Bad}$, and $\mathrm{Bcl}-\mathrm{X}_{\mathrm{L}}$ in the luteolin-treated HL-60 cells in the presence of PDTC. These data indicated that PDTC inhibited luteolin-induced apoptosis by suppressing the activation of the Bcl-2 family members.

\section{Discussion}

Previously, we showed that luteolin induced apoptosis in human leukemia HL-60 cells [11]. By decreasing the membrane potential of the mitochondria and triggering the release of cytochrome $c$ from mitochondira to cytosol, luteolin induced the processing of procaspase- 9 and pocaspase-3, and subsequently leads to the cleavage of poly(ADP-ribose)polymerase (PARP) and DNA fragmentation of factor-45 (DFF-45) [11]. In addition, luteolin induced the cleavage of pro-apoptotic Bcl-2 proteins

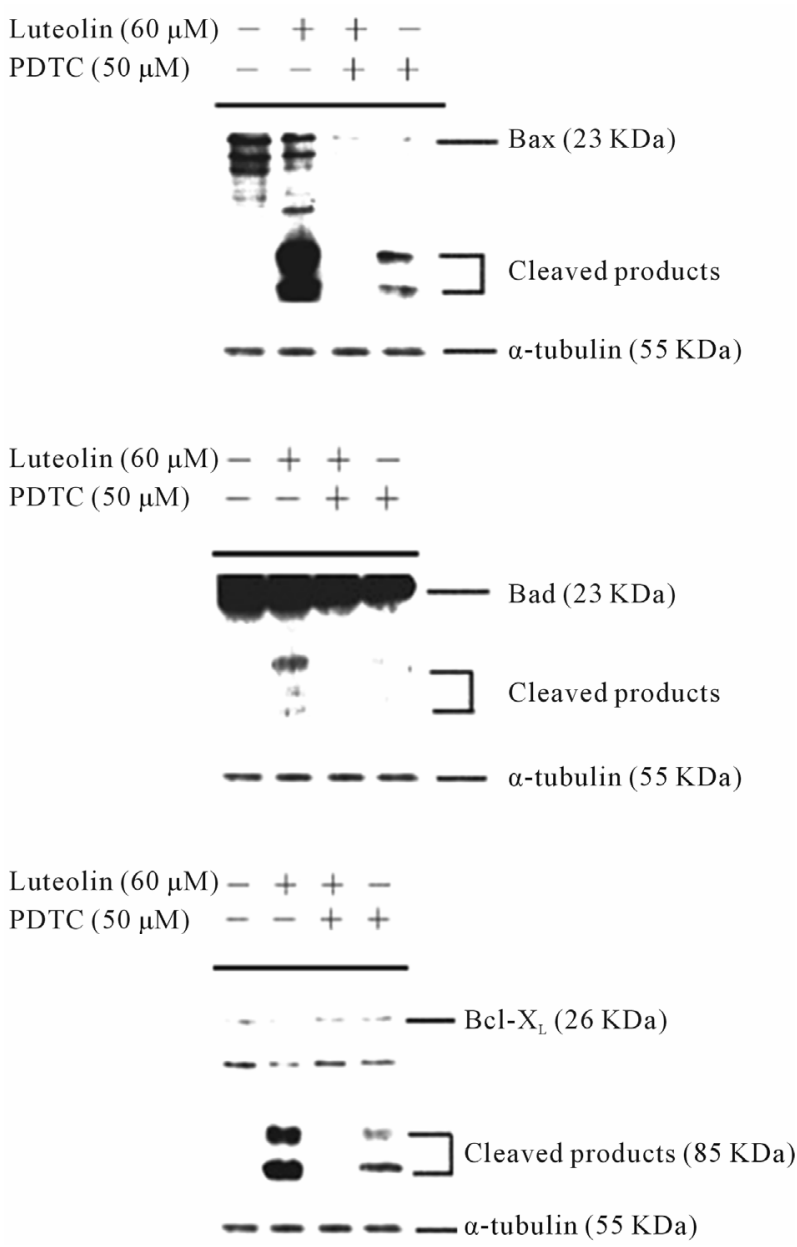

Figure 5. PDTC suppressed the expression of Bax, Bad, and Bcl- $X_{L}$ in luteolin-treated HL-60 cells. HL-60 cells were treated with DMSO, $60 \mu \mathrm{M}$ luteolin, $50 \mu \mathrm{M}$ PDTC followed by $60 \mathrm{mM}$ luteolin, or $50 \mu \mathrm{M}$ PDTC. The expression of Bax, Bad, and $B c l-X_{L}$ was detected by Western blotting analysis using specific antibodies against Bax, Bad, and $B c l-X_{L}$, respectively.

and the cleavage of the anti-apoptotic Bcl-2 proteins [11]. It has been shown that the anti-apoptotic proteins $\mathrm{Bcl}-2$ and $\mathrm{Bcl}-\mathrm{X}_{\mathrm{L}}$ of mammals can be converted into potent pro-apoptotic molecules to further amplify the caspase cascade when they are cleaved [29]. The pro-apoptotic molecule, Bax, exists mainly in cytosol and it can be cleaved to $18 \mathrm{kDa}$ truncated Bax (tBax), a more potent inducer of apoptosis than its wild type during drug-induced apoptosis [30,31]. In this study, we found that, in addition to activation of the mitochondrial pathway [11], luteolin also enhanced the expression of Fas (Figure 4) and the cleavage of caspase- 8 and Bid in both time-dependent and dose-responsive patterns (Figure 2), suggesting an activation of the extrinsic pathway by luteolin.

PDTC, an antioxidant and radical scavenger, has been shown to induce apoptosis in HL-60 cells [25]. In this 
study, we found that either luteolin or PDTC alone increased the expression of Fas and its effector, caspase-8, and activated the Bcl-2 family proteins, whereas the presence of both luteolin and PDTC exhibited the opposite effect (Figures $\mathbf{4}$ and 5). When adding PDTC, we ob- served a reduction of the membrane-bound apoptotic bodies and DNA fragmentation, rather than a synergistic effect on apoptosis, in luteolin-treated HL-60 cells (Figure 3). Previously we have found that PDTC modulated the phosphorylation of Akt and reduces the activity of caspase-9, thereby inhibiting luteolin-induced apoptosis in HL-60 cells [28]. A recent study has shown that Akt regulates Fas-mediated cell death and the intrinsic apoptosis in Jurkat $\mathrm{T}$ lymphocytes [32]. It is possible that the presence of both luteolin and PDTC upregulated Akt, which in turn, blocked the Fas/FasL signaling and the mitochondrial pathway in HL-60 cells. In addition, another group has found that phosphorylation of Akt protects rheumatoid synovial fibroblasts against Fas-induced apoptosis by inhibiting the cleavage of Bid, indicating the connection between the extrinsic and the intrinsic apoptotic pathways in this Fas-mediated apoptosis [33]. It is noteworthy that Bid merges the intrinsic and extrinsic pathways in apoptosis and that PDTC reduced the activation of Bid in luteolin-treated HL-60 cells (Figure 4).

However, PDTC does not appear to interfere with luteolin's ability to change the mitochondrial membrane potential or trigger the release of cytochrome $c$ to cytosol [28], suggesting other player(s) mediate(s) the apoptotic event downstream of cytochrome $c$ at the post-mitochondrial level. A somewhat different setting but relevant finding has been reported previously [34]. Zhou et al. investigated how Akt regulates hybrid motor neuron 1 cells, a neuronal cell line that requires PI 3-kinase/Akt for survival [34]. They found that Akt inhibits cell death and cytochrome $c$-induced caspase activation without blocking the release of cytochrome $c$, suggesting that Akt regulates the suppression of the neural apoptosis at a post-mitochondrial stage, downstream of cytochrome $c$ release, and before activating caspase-9 [34].

Together, our data indicated that PDTC inhibited luteolin-induced apoptosis in both extrinsic and intrinsic pathways (Figure 6), potentially modulated by Akt. Further studies deem necessary to elucidate the regulatory roles of Akt in the combining effect of luteolin and PDTC between the dynamics of apoptosis and cell survival. The combination of luteolin and PDTC increased the survival of the cancer cells rather than reduced the cell number in HL-60 cells. This finding may have clinical implication that the therapeutic effect of anti-cancer medications may not be synergistic, but antagonistic, and should be monitored carefully.

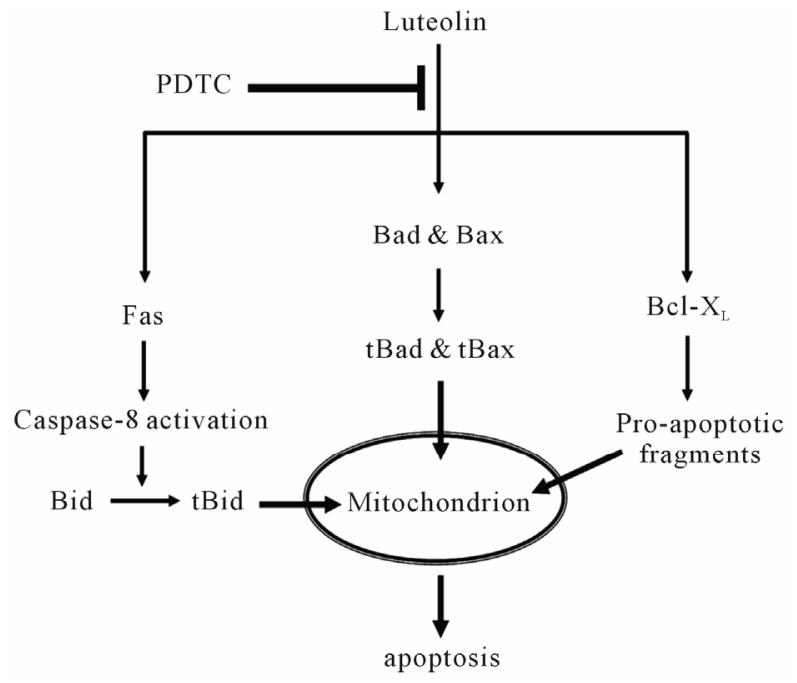

Figure 6. Schematic model of the PDTC suppression effect on luteolin-induced apoptosis in HL-60 cells. PDTC may suppress luteolin-induced apoptosis by inhibiting both the death receptor pathway and the activation of Bad, Bax, and Bcl-X $\mathbf{X}_{\mathbf{L}}$

\section{Acknowledgements}

This work was supported by the grants, NSC98-2320-B309-002-MY3 and NSC101-2320-B-309-001 to MingFen Lee and NSC100-2313-B-309-003 to An-Chin Cheng, from National Science Council (Taiwan).

\section{REFERENCES}

[1] A. Crozier, J. Burns, A. A. Aziz, A. J. Stewart, H. S. Rabiasz, G. I. Jenkins, C. A. Edwards and M. E. Lean, "Antioxidant Flavonols from Fruits, Vegetables and Beverages: Measurements and Bioavailability," Biological Research, Vol. 33, No. 2, 2000, pp. 79-88. doi:10.4067/S0716-97602000000200007

[2] D. F. Birt, S. Hendrich and W. Wang, "Dietary Agents in Cancer Prevention: Flavonoids and Isoflavonoids," Pharmacology \& Therapeutics, Vol. 90, No. 2-3, 2001, pp. 157-177. doi:10.1016/S0163-7258(01)00137-1

[3] C. S. Yang, J. M. Landau, M. T. Huang and H. L. Newmark, "Inhibition of Carcinogenesis by Dietary Polyphenolic Compounds," Annual Review of Nutrition, Vol. 21, 2001, pp. 381-406. doi:10.1146/annurev.nutr.21.1.381

[4] Y. J. Surh, "Cancer Chemoprevention with Dietary Phytochemicals," Nature Reviews Cancer, Vol. 3, No. 10, 2003, pp. 768-780. doi:10.1038/nrc1189

[5] J. A. Ross and C. M. Kasum, "Dietary Flavonoids: Bioavailability, Metabolic Effects, and Safety," Annual Review of Nutrition, Vol. 22, 2002, pp. 19-34. doi:10.1146/annurev.nutr.22.111401.144957

[6] Y. T. Huang, J. J. Hwang, P. P. Lee, F. C. Ke, J. H. Huang, C. J. Huang, C. Kandaswami, E. Middleton Jr. and M. T. Lee, "Effects of Luteolin and Quercetin, In- 
hibitors of Tyrosine Kinase, on Cell Growth and Metastasis-Associated Properties in A431 Cells Overexpressing Epidermal Growth Factor Receptor," British Journal of Pharmacology, Vol. 128, No. 5, 1999, pp. 999-1010. doi:10.1038/sj.bjp.0702879

[7] W. G. Ko, T. H. Kang, S. J. Lee, Y. C. Kim and B. H. Lee, "Effects of Luteolin on the Inhibition of Proliferation and Induction of Apoptosis in Human Myeloid Leukaemia Cells," Phytotherapy Research, Vol. 16, No. 3, 2002, pp. 295-298. doi:10.1002/ptr.871

[8] H. W. Leung, C. H. Wu, C. H. Lin and H. Z. Lee, "Luteolin Induced DNA Damage Leading to Human Lung SquaMous Carcinoma CH27 Cell Apoptosis," European Journal of Pharmacology, Vol. 508, No. 1-3, 2005, pp. 77-83. doi:10.1016/j.ejphar.2004.12.032

[9] R. X. Shi, C. N. Ong and H. M. Shen, "Protein Kinase C Inhibition and $\mathrm{x}$-Linked Inhibitor of Apoptosis Protein Degradation Contribute to the Sensitization Effect of Luteolin on Tumor Necrosis Factor-Related Apoptosis-Inducing Ligand-Induced Apoptosis in Cancer Cells," Cancer Research, Vol. 65, No. 17, 2005, pp. 7815-7823.

[10] C. P. Xavier, C. F. Lima, A. Preto, R. Seruca, M. Fernandes-Ferreira and C. Pereira-Wilson, "Luteolin, Quercetin and Ursolic Acid Are Potent Inhibitors of Proliferation and Inducers of Apoptosis in both KRAS and BRAF Mutated Human Colorectal Cancer Cells," Cancer Letters, Vol. 281, No. 2, 2009, pp. 162-170. doi:10.1016/j.canlet.2009.02.041

[11] A. C. Cheng, T. C. Huang, C. S. Lai and M. H. Pan, "Induction of Apoptosis by Luteolin through Cleavage of Bcl-2 Family in Human Leukemia HL-60 Cells," European Journal of Pharmacology, Vol. 509, No. 1, 2005, pp. 1-10. doi:10.1016/j.ejphar.2004.12.026

[12] A. M. Komarov, I. T. Mak and W. B. Weglicki, "Iron Potentiates Nitric Oxide Scavenging by Dithiocarbamates in Tissue of Septic Shock Mice," Biochimica Biophysica Acta, Vol. 1361, No. 3, 1997, pp. 229-234. doi:10.1016/S0925-4439(97)84636-4

[13] A. B. Nathens, R. Bitar, C. Davreux, M. Bujard, J. C. Marshall, A. P. Dackiw, R. W. Watson and O. D. Rotstein, "Pyrrolidine Dithiocarbamate Attenuates EndotoxinInduced Acute Lung Injury," American Journal of Respiratory Cell and Molecular Biology, Vol. 17, No. 5, 1997, pp. 608-616.

[14] S. Verhaegen, A. J. McGowan, A. R. Brophy, R. S. Fernandes and T. G. Cotter, "Inhibition of Apoptosis by Antioxidants in the Human HL-60 Leukemia Cell Line," Biochemical Pharmacology, Vol. 50, No. 7, 1995, pp. 1021-1029. doi:10.1016/0006-2952(95)00233-P

[15] D. Moellering, J. McAndrew, H. Jo and V. M. DarleyUsmar, "Effects of Pyrrolidine Dithiocarbamate on Endothelial Cells: Protection against Oxidative Stress," Free Radical Biology \& Medicine, Vol. 26, No. 9-10, 1999, pp. 1138-1145. doi:10.1016/S0891-5849(98)00300-1

[16] F. Di Nicuolo, S. Serini, A. Boninsegna, P. Palozza and G. Calviello, "Redox Regulation of Cell Proliferation by Pyrrolidine Dithiocarbamate in Murine Thymoma Cells Transplanted in Vivo," Free Radical Biology \& Medicine,
Vol. 31, No. 11, 2001, pp. 1424-1431. doi:10.1016/S0891-5849(01)00714-6

[17] C. I. Nobel, M. Kimland, B. Lind, S. Orrenius and A. F. Slater, "Dithiocarbamates Induce Apoptosis in Thymocytes by Raising the Intracellular Level of Redox-Active Copper," The Journal of Biological Chemistry, Vol. 270, No. 44, 1995, pp. 26202-26208. doi: $10.1074 /$ jbc. 270.44 .26202

[18] P. Brennan and L. A. O’Neill, “2-Mercaptoethanol Restores the Ability of Nuclear Factor Kappa B (NF Kappa B) to Bind DNA in Nuclear Extracts from Interleukin 1-Treated Cells Incubated with Pyrollidine Dithiocarbamate (PDTC). Evidence for Oxidation of Glutathione in the Mechanism of Inhibition of NF Kappa B by PDTC," The Biochemical Journal, Vol. 320, 1996, pp. 975-981.

[19] W. Erl, C. Weber and G. K. Hansson, "Pyrrolidine Dithiocarbamate-Induced Apoptosis Depends on Cell Type, Density, and the Presence of $\mathrm{Cu}(2+)$ and $\mathrm{Zn}(2+)$," American Journal of Physiology Cell Physiology, Vol. 278, No. 6, 2000, pp. C1116-C1125.

[20] R. Bessho, K. Matsubara, M. Kubota, K. Kuwakado, H. Hirota, Y. Wakazono, Y. W. Lin, A. Okuda, M. Kawai, R. Nishikomori, et al., "Pyrrolidine Dithiocarbamate, a Potent Inhibitor of Nuclear Factor Kappa B (NF-Kappa B) Activation, Prevents Apoptosis in Human Promyelocytic Leukemia HL-60 Cells and Thymocytes," Biochemical Pharmacology, Vol. 48, No. 10, 1994, pp. 1883-1889. doi:10.1016/0006-2952(94)90586-X

[21] H. S. Chung, H. J. Jeong, S. H. Hong, M. S. Kim, S. J. Kim, B. K. Song, I. S. Jeong, E. J. Lee, J. W. Ahn, S. H. Baek and H. M. Kim, "Induction of Nitric Oxide Synthase by Oldenlandia Diffusa in Mouse Peritoneal Macrophages," Biological \& Pharmaceutical Bulletin, Vol. 25, No. 9, 2002, pp. 1142-1146. doi:10.1248/bpb.25.1142

[22] M. Grafe, G. Steinheider, U. Desaga, C. Warnecke, H. B. Lehmkuhl, V. Regitz-Zagrosek, A. G. Hildebrandt and E. Fleck, "Characterization of Two Distinct Mechanisms for Induction of Apoptosis in Human Vascular Endothelial Cells," Clinical Chemistry and Laboratory Medicine, Vol. 37, No. 5, 1999, pp. 505-510. doi:10.1515/CCLM.1999.081

[23] C. C. Hu, C. H. Hsiao, S. Y. Huang, S. H. Fu, C. C. Lai, T. M. Hong, H. H. Chen and F. J. Lu, "Antioxidant Activity of Fermented Soybean Extract," Journal of Agricultural and Food Chemistry, Vol. 52, No. 18, 2004, pp. 5735-5739. doi:10.1021/jf035075b

[24] R. Li, D. J. Bounds, D. Granville, S. H. Ip, H. Jiang, P. Margaron and D. W. Hunt, "Rapid Induction of Apoptosis in Human Keratinocytes with the Photosensitizer QLT0074 via a Direct Mitochondrial Action," Apoptosis, Vol. 8, No. 3, 2003, pp. 269-275. doi:10.1023/A:1023624922787

[25] F. Della Ragione, V. Cucciolla, A. Borriello, V. Della Pietra, C. Manna, P. Galletti and V. Zappia, "Pyrrolidine Dithiocarbamate Induces Apoptosis by a Cytochrome c-Dependent Mechanism," Biochemical and Biophysical Research Communications, Vol. 268, No. 3, 2000, pp. 942-946. doi:10.1006/bbrc.2000.2161 
[26] J. L. Herrmann, A. W. Beham, M. Sarkiss, P. J. Chiao, M. T. Rands, E. M. Bruckheimer, S. Brisbay and T. J. McDonnell, "Bcl-2 Suppresses Apoptosis Resulting from Disruption of the NF-Kappa B Survival Pathway," Experimental Cell Research, Vol. 237, No. 1, 1997, pp. 101109. doi:10.1006/excr.1997.3737

[27] J. S. Thompson, R. Asmis, A. A. Tapp, B. Nelson, Y. Chu, J. Glass, M. Moneyhon and S. A. Brown, "Pyrrolidine Dithiocarbamate (PDTC) Blocks Apoptosis and Promotes Ionizing Radiation-Induced Necrosis of FreshlyIsolated Normal Mouse Spleen Cells," Apoptosis, Vol. 15, No. 6, 2010, pp. 705-714. doi:10.1007/s10495-010-0487-7

[28] A. C. Cheng, T. C. Huang, C. S. Lai, J. M. Kuo, Y. T. Huang, C. Y. Lo, C. T. Ho and M. H. Pan, "Pyrrolidine Dithiocarbamate Inhibition of Luteolin-Induced Apoptosis through Up-Regulated Phosphorylation of Akt and Caspase-9 in Human Leukemia HL-60 Cells," Journal of Agricultural and Food Chemistry, Vol. 54, No. 12, 2006, pp. 4215-4221. doi:10.1021/jf060269n

[29] D. S. Bellows, B. N. Chau, P. Lee, Y. Lazebnik, W. H. Burns and J. M. Hardwick, "Antiapoptotic Herpesvirus Bcl-2 Homologs Escape Caspase-Mediated Conversion to Proapoptotic Proteins," Journal of Virology, Vol. 74, No. 11, 2000, pp. 5024-5031. doi:10.1128/JVI.74.11.5024-5031.2000
[30] D. E. Wood, A. Thomas, L. A. Devi, Y. Berman, R. C. Beavis, J. C. Reed and E. W. Newcomb, "Bax Cleavage Is Mediated by Calpain during Drug-Induced Apoptosis," Oncogene, Vol. 17, No. 9, 1998, pp. 1069-1078. doi:10.1038/sj.onc.1202034

[31] H. Toyota, N. Yanase, T. Yoshimoto, M. Moriyama, T. Sudo and J. Mizuguchi, "Calpain-Induced Bax-Cleavage Product Is a More Potent Inducer of Apoptotic Cell Death than Wild-Type Bax," Cancer Letters, Vol. 189, No. 2, 2003, pp. 221-230. doi:10.1016/S0304-3835(02)00552-9

[32] S. M. Uriarte, S. Joshi-Barve, Z. Song, R. Sahoo, L. Gobejishvili, V. R. Jala, B. Haribabu, C. McClain and S. Barve, "Akt Inhibition Upregulates FasL, Downregulates c-FLIPs and Induces Caspase-8-Dependent Cell Death in Jurkat T Lymphocytes," Cell Death and Differentiation, Vol. 12, No. 3, 2005, pp. 233-242. $\underline{\text { doi: } 10.1038 / \text { sj.cdd.4401549 }}$

[33] S. Garcia, M. Liz, J. J. Gomez-Reino and C. Conde, “Akt Activity Protects Rheumatoid Synovial Fibroblasts from Fas-Induced Apoptosis by Inhibition of Bid Cleavage,' Arthritis Research \& Therapy, Vol. 12, No. 1, 2010, pp. R33. doi:10.1186/ar2941

[34] H. Zhou, X. M. Li, J. Meinkoth and R. N. Pittman, “Akt Regulates Cell Survival and Apoptosis at a Postmitochondrial Level," The Journal of Cell Biology, Vol. 151, No. 3, 2000, pp. 483-494. doi:10.1083/jcb.151.3.483 